\title{
Childbirth and motherhood in women with motor disability due to a rare condition: an exploratory study
}

\author{
Marc Dommergues ${ }^{1 *}\left(\mathbb{D}\right.$, Drina Candilis ${ }^{2}$, Ludivine Becerra ${ }^{3}$, Edith Thoueille ${ }^{3}$, David Cohen ${ }^{4}$ and \\ Sylvie Viaux-Savelon ${ }^{4}$
}

\begin{abstract}
Background: Rare diseases may result in motor impairment, which in turn may affect parenthood. Our purpose was to evaluate perinatal outcomes, parenting needs, mother-infant interactions and infant development in a set of volunteer women with motor impairment due to a rare disease. In a parenting support institution, we recruited a consecutive series of 22 volunteer pregnant women or young mothers, recorded perinatal outcomes, and followed mother-infant interaction and relationship and infant development up to 14 months postpartum. Cases with intellectual or psychic disability were not included.
\end{abstract}

Results: There were 11 genetic diseases (2 Spinal Muscular Atrophy, 1 Charcot-Marie-Tooth, 1 autosomal dominants myopathy, 1 mitochondrial disease, 2 Elhers-Danlos, 1 Friedreich ataxia, 1 spinocerebellar ataxia, 1 tetrahydrobiopterine deficiency, 1 Ectrodactyly), and 11 rare non-genetic conditions (2 spine tumors, 2 strokes, 1 juvenile chronic arthritis, 3 birth injuries, 1 inflammatory myopathy, 1 congenital amputation, and 1 traumatic amputation). These resulted in 10 impairments of four limbs, 4 impairments of both lower limbs, 7 unilateral impairments, and one distal tremor. Social deprivation Epices score, Cutrona social support scale, Edinburg Postnatal Depression scale, and Spielberger State/Trait Anxiety Inventory were unremarkable. Perinatal outcome: 4 gestational diabetes, 1 pre-eclampsia, 9 caesareans, 6 assisted and 7 spontaneous vaginal deliveries, 20 term live-births and 2 premature deliveries (35-36 weeks). Twelve women declared they were self-sufficient for daily activities; six declared they were self-sufficient to provide basic care to their baby. Distribution of the Brunet-Lezine child development score was normal. The parent-infant relationship global assessment scale (PIR-GAS) was well adapted in 2 cases, adapted in 8, perturbed in 7, significantly perturbed in 2, and distressed in 3 (mean 71.8; 95\% Cl 49.6-93.9). This was unrelated to any somatic or emotional characteristics of the participants. Coding interactive behavior revealed that infant engagement was lower and infant avoidance greater than in controls $(p<0.05)$.

Conclusion: Infant development was normal, but mother-infant interactions were altered in half of the participants independently from the degree of motor impairment, underscoring the need for parenting support, even for parents who are self-sufficient in daily activities.

\footnotetext{
*Correspondence: marc.dommergues@aphp.fr;

marc.dommergues@gmail.com

${ }^{1}$ Department of Obstetrics and Gynecology, Hopital Pitié Salpêtrière

APHP and Sorbonne Université, 83 Boulevard de l'Hopital, 75013 Paris, France

Full list of author information is available at the end of the article
} permits use, sharing, adaptation, distribution and reproduction in any medium or format, as long as you give appropriate credit to the original author(s) and the source, provide a link to the Creative Commons licence, and indicate if changes were made. The images or other third party material in this article are included in the article's Creative Commons licence, unless indicated otherwise in a credit line to the material. If material is not included in the article's Creative Commons licence and your intended use is not permitted by statutory regulation or exceeds the permitted use, you will need to obtain permission directly from the copyright holder. To view a copy of this licence, visit http://creativecommons.org/licenses/by/4.0/. The Creative Commons Public Domain Dedication waiver (http://creativeco mmons.org/publicdomain/zero/1.0/) applies to the data made available in this article, unless otherwise stated in a credit line to the data. 
Keywords: Rare disease, Disability, Motherhood, Motor impairment Tetraplegia Hemiplegia Amputation, Birth, Parent-infant interaction and relationship, Child development

\section{Background}

About $10 \%$ of women of childbearing age are living with a disability that impedes their daily activities [1-4]. Among them, due to improved medical care, a growing number of women affected with a rare disease now reach childbearing age and have the same well-founded desire to become a mother as other women. Their ability to provide a safe environment for their child may be questioned by their families or by professionals, including social workers, nurses, midwives, or doctors [5-8]. When impairment results from a rare condition, women may face puzzled healthcare providers, who fear severe complications might occur should their patients become pregnant. Besides, women with disabilities often fail to obtain financial support to help them gain independence as caregivers to their children. These difficulties partly result from the scarcity of data on pregnancy, parenthood, and children's outcomes in women affected by a rare disease with a motor expression. Our goal was to provide a new insight in that matter. Therefore, we recruited volunteers attending our parenting support facility for disabled persons, who consented to report on their experience as parents, have their child's development assessed, have their infant screened for withdrawal, and undergo assessment of mother-infant relationship and interaction.

\section{Methods}

\section{Aim, design, setting}

Exploratory observational study conducted in a parenting support facility dedicated to disabled parents and future parents.

\section{Characteristic of participants}

Between March 2016 and August 2017, we recruited participants among pregnant women or young mothers referred for parenting support. We followed pregnant women at least 3 months and up to 12 months postpartum, and recorded their perinatal data prospectively. For participants included in the post-partum period, we recorded perinatal data retrospectively.

Potentially eligible women received verbal and written information regarding the study. Additional information was provided to those who expressed interest, together with their partner if applicable. They gave written consent to participate. A specific consent form was signed for authorizing video of mother-child interactions. When applicable, the participant's partner or the co-parent signed a consent form for the collection of information on their child and the recording of videos.

Inclusion criteria were maternal age 18 or greater, being either pregnant $>14$ weeks, or mother of a child $<1$ year, having motor disability due to a rare condition, and written consent to enroll. In compliance with French laws, the absence of health insurance coverage precluded participation in the study. Further exclusion criteria were intellectual disability, psychiatric disorder, or lack of fluency in French. The inclusion visit took place either pre or postnatally, immediately before a planned parenting support visit.

One hundred and fifteen pregnant women with motor disabilities and/or rare conditions were eligible. Twentynine consented to participate. Two were excluded because of pre-existing psychiatric disorders. One was excluded because of mild intellectual disability. Four declined to be monitored following inclusion. Twentytwo women had a complete follow-up and formed our dataset. Of these, 15 consented to be videotaped with their infant.

\section{Processes and variables}

At inclusion, data were collected based on medical records and self-administered questionnaires. The investigator helped the participant if she felt it difficult to handle the forms.

We recorded the following variables:

\section{Motor impairment and disability}

The name of the disease affecting the patient was recorded based on the participant's declaration and on the specifications of her medical record. We used the Barthel index (BI) as a measure of functional independence in activities of daily living [9]. Participants declared if they felt independent, or needed help, when performing the following activities: feeding, bathing, dressing, bowel movements, bladder control, toilet use, transfers (bed to chair and back), and mobility. This resulted in a score ranging from zero (completely dependent) to 100 (completely independent). We did not modify scoring based on our own observations.

We also asked participants if they felt they were independent or needed help for each of the following parenting activities: changing or bathing, feeding, outing, dressing, playing, cuddling, and calming down a crying baby. For each activity, participants declared if they were independent (with or without an adapted 
environment), could do the activity with help, or were unable to do it. Eventually this enabled us to identify two groups of participants: those who considered they were independent for all baby-care activities and those who declared they needed help for at least one activity. We included a detailed description of the number of body parts with motor impairment and additional non-motor impairment.

\section{Obstetrical and perinatal data}

We recorded obstetrical history and pregnancy outcomes based on the declaration of participants and on their medical records.

\section{Social context}

Social context was assessed based on marital status, housing, source of income, education level, the Epices score of social deprivation $[10,11]$ and the Cutrona scale for social support $[12,13]$.

\section{Emotional status}

We assessed maternal emotional status at inclusion and during the postnatal visit. At inclusion, we used the State Trait Anxiety Inventory (STAI)-A for anxiety level, the STAI-B for anxiety trait [14-16]. At the post-natal visit we used the State Trait Anxiety Inventory (STAI)-A for anxiety level, and the Edinburg Postnatal Depression (EPDS) scale [17] for depressive mood. Participants were considered as depressed when EPDS score was greater than $12[18,19]$. Anxiety was considered high when STAI score was greater than 42 [14].

\section{Child development and mother-infant interaction}

The postnatal visit took place between 3 and 13 months after delivery. One of the authors (LB, a clinical psychologist) made an appointment with the mother either at home (21 cases) or at the parenting support center (one case). She assessed child psychomotor development using the Brunet Lézine scale. This scale, designed for 2-30 month infants, analyses motor or postural development, eye-hand coordination, vocalization, and sociability. Combining these items results in a global developmental score [20, 21].

Infant withdrawal was assessed by LB using the Guedeney and Fermanian Modified Alarm Distress Baby Scale, M-ADBB [22-24]. Briefly, m-ADBB is a screening tool including only five areas: (a) facial expression, (b) eye contact, (c) vocalization, (d) activity level, and (e) relationship. In addition, the scoring is changed to three global levels: "Satisfactory," "Possible problem," or "Definite problem" for each area. "Definite problem" or two "Possible problems" on the $\mathrm{m}$-ADBB indicates that the infant required further assessment.
The mother-infant relationship was assessed by LB based on a clinical evaluation using the parent-infant relationship global assessment scale (PIR-GAS) [25]. The PIR-GAS allows for a global rating of the quality of a parent-infant (or parent-child) relationship on a numerical scale, with higher scores indicating higher relationship quality. We used the original score, which classifies the quality of relationship as follows. 90: well adapted, 80: adapted, 70: perturbed, 60 significantly perturbed, 50: distressed, 40: disturbed, 30: disordered, 20: severely disordered, and 10: grossly impaired [26].

When parents gave consent, mother-infant interactions were videotaped. Mothers freely fed or played with their child either at home or at the parenting support center. Videos were analyzed offline by a trained child psychiatrist (SVS) blinded to the perinatal history, using the Coding Interactive Behavior (CIB) New-born and Feeding Scale [27, 28] using a validated French version [29]. The CIB is a global rating system of parent-child interaction that contains micro-level codes and global rating scales. Each code is rated from 1 (a little) to 5 (a lot). Forty-two different codes are grouped into several interactive composites. Six composites were used in the current study focusing on the mother $(\mathrm{N}=2)$, the infant $(\mathrm{N}=2)$ and the dyad $(\mathrm{N}=2)$. (1) Maternal sensitivity was the average of maternal acknowledgment of infant interactive signals, imitation and elaboration of the infant's behavior, gaze directed to the infant or joint activity, appropriate tone of voice/motherese, expression of appropriate range of affect, resourcefulness in dealing with infant negative states, affectionate touch, supportive presence, and infant-led interaction, i.e. mother focusing on the child's needs and state. (2) Maternal intrusiveness was the average of maternal inappropriate physical manipulation, mother overriding behavior (i.e. mother disregarding the infant's signals and interrupting the infant's ongoing behavior), maternal anxiety, maternal negative affect/anger toward the baby, maternal criticizing of infant's behavior, and mother-led interaction (i.e. interactions being led by the mother's needs rather than infant's needs, pace, and agenda). (3) Dyadic reciprocity was the average of the mother's elaboration of the infant's vocalizations and movements, maternal gaze directed to the infant, child gaze directed to mother or joint activity, verbal praise of the infant's behavior, affectionate touch and enthusiasm, infant vocalization, warm and positive affect for both parent and child, dyadic adaptationregulation, and fluency of the interaction. (4) Negative dyadic status was the average of maternal negative affect/ anger, mother's hostility behavior, child's negative or labile affect, withdrawal of the infant from the environment, dyad constriction, and expression of tension. (5) Infant avoidance was the average of the child's avoidance 
behavior toward the mother, child's negative and labile affect, and withdrawal from the environment. (6) Infant social engagement was the average of joint attention, child positive affect, affection to parent, alertness, low fatigue, vocalizations/verbal output, initiation, competent use of the environment, and infant-led interaction.

During the post-partum visit, we also recorded somatic and psychological events that occurred before pregnancy, during pregnancy, and post-partum. We recorded the needs expressed by women regarding medical care, psychological, social, and environmental support (selfadministered questionnaire). We recorded child protection legal decisions if applicable.

\section{Statistical analysis and data management}

We used an electronic research form from Ad Scientiam, Paris, France (https://www.adscientiam.fr/). Data were stored anonymously, according to a procedure authorized by the Comité Consultatif sur le traitement de l'information en matière de recherche or CCTIRS, an independent agency of the French government. Most statistics were descriptive and exploratory. To compare the distribution of CIB dimensions to that of controls, we used videos from dyads enrolled as controls in a previous study [30]. We compared the median score for each dimension in the 15 cases who consented to video recordings to 13 controls using a bilateral Mann and Whitney non-parametric test. Statistics were run using StatView, Abacus Concept California USA.

\section{Results}

\section{Mothers' medical characteristics}

Maternal age ranged from 26 to 41 years (mean 31,6 years). Ten women were included during pregnancy and 12 in the postnatal period. Eleven participants were primigravidae. Eleven had had a previous pregnancy, of which 7 had had 1, one had had 2, and three had had 3 previous pregnancies. Out of the 18 previous pregnancies, there were 7 spontaneous fetal losses $<24$ weeks, two abortions for social reasons, 1 intrauterine death $>24$ weeks, 1 premature live birth, and 7 term live births.

The type of motor impairment is displayed on Table 1. Associated disabilities and Barthel Indexes are displayed on Table 2.

Regarding emotional status at inclusion the mean Spielberger YB trait score was 42.6 (SD 9.7). It was greater than 42 in 9 cases (range 50-68). The mean Spielberger YA state score was 41.1 (SD 15.2). It was greater than 42 in 10 cases (range 48-61).

At the post-natal visit, the mean EPDS score was 6.2 (SD 4.2). It was greater than 12 in two cases (13 and 16) and greater than 10 in three. The mean Spielberger YA state score was 34.7 (SD 12.0). It was greater than 42 in 5 cases (range 44-68).

\section{Social context}

Twenty-one participants lived with a husband or partner. One was single. Six worked full time and 4 part-time, 3 were unemployed, 1 was a student, and 8 declared they were housewives. Seventeen of their partners worked full time and four were unemployed. One partner had epidermolysis bullosa. The others did not suffer from any chronic disease. Fifteen participants received social benefits. Twenty lived in their own home, and two lived at the home of a relative. Fifteen considered their home was adapted to their disability, and 7 declared it was not.

Educational level was as follows: graduated after three years or more of university $(n=11)$, graduated after two years of university, which is grossly equivalent to college graduation in the USA $(n=3)$, passed the final high school examination but did not attend university $(n=4)$, did not pass the final high school examination $(n=4)$.

Regarding social deprivation, 7/22 (32\%) had an Epices score above 30 , i.e. belonged to the quintiles 4 and 5 of social deprivation in France (4). The mean Cutrona social support score was 77 (SEM 1.9; SD 9.0), similar to what is expected in the general population (7).

\section{Obstetrical history and perinatal outcome}

Twenty-one pregnancies were spontaneous, and one resulted from intrauterine insemination. Nineteen pregnancies were planned; three were unplanned, yet welcome.

Regarding obstetrical complications, there were 4 gestational diabetes, one pre-eclampsia. There were 9 caesareans, 6 assisted vaginal deliveries, and 7 spontaneous vaginal deliveries. Epidural or spinal anesthesia was provided in 16 cases, 4 women labored under opioids, and two caesarean sections were performed under general anesthesia.

Participants gave birth to 13 girls and 9 boys. Eight were bottle-fed, 14 were breast-fed. There were 20 live births at term and 2 premature deliveries at 35 and 36 weeks. One neonate required resuscitation maneuvers in the labor ward. Twenty-one did not: two had 5-min Apgar scores at 9 and nineteen at 10. Four neonates were transferred to the NICU ( 2 respiratory distresses, 1 hypoglycemia, 1 cephalhematoma). All babies were eventually alive and well at discharge. They all lived with their mothers. No legal measures were taken for child protection.

\section{Child development and mother-infant interaction}

We performed the post-natal visit at three months in 10 cases, at four months in two, at eleven months in two, and at twelve months in 8 . 
Table 1 Motor impairment

\begin{tabular}{|c|c|c|c|c|c|c|}
\hline Case number & Type of impairment & $\begin{array}{l}\text { Movement } \\
\text { disorders }\end{array}$ & Disease & Pathophysiology & Transmission & Risk for offspring \\
\hline \multicolumn{7}{|c|}{ Bilateral upper and lower limbs } \\
\hline 1 & Tetraparesis & No & $\begin{array}{l}\text { Type } 2 \text { spinal muscular } \\
\text { atrophy }\end{array}$ & Genetic & Autosomal recessive & Low \\
\hline 2 & Tetraparesis & Yes & $\begin{array}{l}\text { Type } 2 \text { spinal muscular } \\
\text { atrophy }\end{array}$ & Genetic & Autosomal recessive & Low \\
\hline 3 & Tetraparesis & Yes & Mitochondrial disorder & Genetic & Mitochondrial & Uncertain \\
\hline 4 & Tetraparesis & Yes & $\begin{array}{l}\text { Charcot Marie Tooth } \\
\text { disease }\end{array}$ & Genetic & Autosomal recessive & Low \\
\hline 5 & Tetraparesis & No & $\begin{array}{l}\text { Autosomal dominant } \\
\text { Myopathy }\end{array}$ & Genetic & Autosomal dominant & High \\
\hline 6 & Tetraparesis & Yes & $\begin{array}{l}\text { Cervical Hemangioma, } \\
\text { C2-C3 }\end{array}$ & Stroke & Not applicable & N/A \\
\hline 7 & Bone/joints disorders & No & Juvenile chronic arthritis & Inflammatory & Not applicable & N/A \\
\hline 8 & Bone/joints disorders & No & Ehlers-Danlos Syndrome & Genetic & Autosomal dominant & High \\
\hline 9 & Bone/joints disorders & No & Ehlers-Danlos Syndrome & Genetic & Autosomal dominant & High \\
\hline 10 & Ectrodactyly & No & $\begin{array}{l}\text { Ectrodactyly of left upper } \\
\text { limb, agenesis of right } \\
\text { lower limb and left upper } \\
\text { limb }\end{array}$ & Genetic & $\begin{array}{l}\text { Possibly autosomal domi- } \\
\text { nant }\end{array}$ & Uncertain \\
\hline \multicolumn{7}{|l|}{ Unilateral } \\
\hline 11 & Congenital Hemiplegia & Yes & Cerebral palsy & Birth asphyxia & Not applicable & N/A \\
\hline 12 & Congenital Hemiplegia & Yes & Brain malformation & Malformation & Not applicable & N/A \\
\hline 13 & Hemiparesis & Yes & Left hemiparesis & Stroke & Not applicable & N/A \\
\hline 14 & Upper limb paresis & No & Brachial plexus birth injury & Birth injury & Not applicable & N/A \\
\hline 15 & Upper limb paralysis & Yes & Brachial plexus birth injury & Birth injury & Not applicable & N/A \\
\hline 16 & Amputation & No & $\begin{array}{l}\text { Congenital agenesis of a } \\
\text { forearm }\end{array}$ & Malformation & Not applicable & N/A \\
\hline 17 & Amputation & No & $\begin{array}{l}\text { Traumatic amputation of } \\
\text { an arm }\end{array}$ & Trauma & Not applicable & N/A \\
\hline \multicolumn{7}{|c|}{ Bilateral lower limbs } \\
\hline 18 & Paraparesis & Yes & Friedreich's ataxia & Genetic & Autosomal recessive & Low \\
\hline 19 & Paraparesis & Yes & Spinocerebellar ataxia & Genetic & Autosomal dominant & High \\
\hline 20 & Paraparesis & No & Autoimmune myopathy & inflammatory & Not applicable & Low \\
\hline 21 & Brown-Sequard syndrome & No & Spinal astrocytoma & Tumor & Not applicable & Low \\
\hline \multicolumn{7}{|c|}{ Movement disorder } \\
\hline 22 & Distal tremor & yes & $\begin{array}{l}\text { Tetrahydrobiopterin defi- } \\
\text { ciency }\end{array}$ & Genetic & Autosomal recessive & Low \\
\hline
\end{tabular}

N/A not applicable

As for mothers' self-perception regarding independence for baby care activities, 21 participants declared they felt independent when playing with their baby, 20 when cuddling, 19 when feeding, 19 when calming the baby, 15 when dressing it, 12 when taking it on outings, and 10 when performing body care such as changing, cleaning or bathing the baby. Only 6 participants declared they considered themselves as independent during all the above activities. Declared independence regarding baby care activities did not correlate with the reported functional independence for self-care as assessed by the Barthel Index (Fig. 1).
Child development as assessed by the distribution of the Brunet Lezine score was within normal range for all infants (mean, 99.8; range 91-109) Regarding the M-ADBB withdrawal scale, no infant was considered as having a "definite problem" and 5/22 (22\%) were considered as having two "possible problems", i.e. were positive for withdrawal screening. Based on PIR-GAS scoring, the mother-infant relationship was considered well adapted in 2 cases, adapted in 8 , perturbed in 7 , significantly perturbed in 2, and distressed in 3, with a mean score of 71.8 (95\% confidence interval: 49.6-93.9). The five infants positive for M-ADBB withdrawal screening belonged 
Table 2 Associated non-motor disabilities, Barthel index, and previous children

\begin{tabular}{|c|c|c|c|c|c|c|c|c|}
\hline Case number & Dyspnea & Impaired vision & $\begin{array}{l}\text { Impaired } \\
\text { hearing }\end{array}$ & Hypoesthesia & Pain (past week) & $\begin{array}{l}\text { Speech } \\
\text { impairment }\end{array}$ & Barthel Index & Prev. children \\
\hline 1 & Yes & No & No & No & 4/10 and less & No & 30 & 0 \\
\hline 2 & Yes & No & No & No & $5 / 10$ and less & No & 30 & 0 \\
\hline 3 & No & No & No & No & 4/10 and less & No & 90 & 0 \\
\hline 4 & No & No & No & Yes & $5 / 10$ and less & No & 60 & 1 \\
\hline 5 & No & No & No & No & 4/10 and less & No & 100 & 0 \\
\hline 6 & No & No & No & No & $5 / 10$ and less & No & 95 & 0 \\
\hline 7 & Yes & No & No & No & $4 / 10$ and less & No & 50 & 0 \\
\hline 8 & Yes & No & Yes & Yes & $5 / 10$ and less & No & 70 & 0 \\
\hline 9 & Yes & No & No & Yes & 4/10 and less & No & 100 & 1 \\
\hline 10 & No & No & No & No & $5 / 10$ and less & No & 85 & 0 \\
\hline 11 & No & No & Yes & Yes & $5 / 10$ and less & No & 60 & 2 \\
\hline 12 & No & No & No & No & 4/10 and less & Yes & 75 & 0 \\
\hline 13 & No & Yes & No & Yes & $5 / 10$ and less & Yes & 95 & 2 \\
\hline 14 & No & No & No & Yes & 4/10 and less & No & 100 & 0 \\
\hline 15 & No & No & No & Yes & $5 / 10$ and less & No & 90 & 0 \\
\hline 16 & No & No & No & No & $5 / 10$ and less & No & 100 & 0 \\
\hline 17 & No & No & No & Yes & $5 / 10$ and less & No & 100 & 0 \\
\hline 18 & No & No & Yes & No & $4 / 10$ and less & Yes & 55 & 0 \\
\hline 19 & No & Yes & Yes & No & $4 / 10$ and less & Yes & 90 & 0 \\
\hline 20 & No & No & No & No & 4/10 and less & No & 85 & 0 \\
\hline 21 & No & No & No & Yes & 5/10 and less & No & 95 & 2 \\
\hline
\end{tabular}

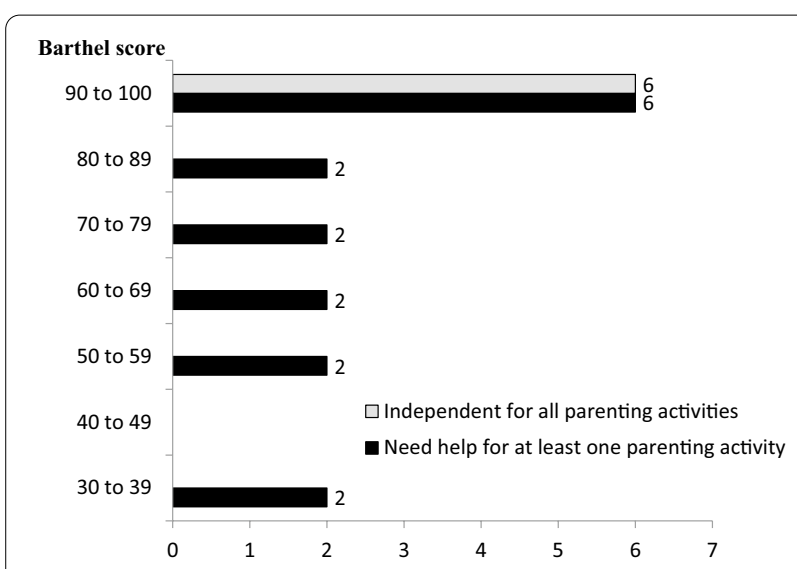

Fig. 1 Barthel index and independence for parenting activities. Note: All women with Barthel score $<90$ (i.e. dependent for daily activity) felt dependent for at least one parenting activity. Six of 12 women with Barthel score $\geq 90$ (i.e. independent or nearly independent for daily activity) felt dependent for at least one parenting activity to dyads with perturbed $(\mathrm{n}=2)$, significantly perturbed $(n=2)$ or distressed $(n=1)$ mother-infant relationships assessed by the PIR-GAS score. PIR-GAS scores were not correlated to the degree of motor impairment (Fig. 2), to the independence women perceived in their activities of daily living (Bathel index), to the age at which the disease

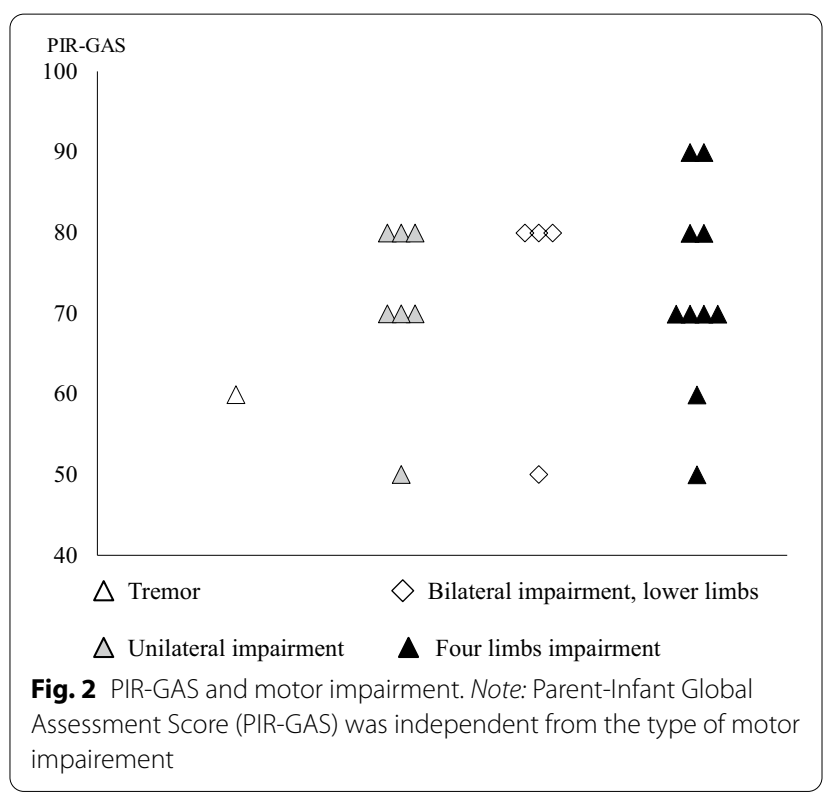

started, to the indices of social support or of social deprivation, or to the scores of anxiety and depression (data not shown).

Finally, Fig. 3 displays the distribution of CIB scores in participants compared to controls. The median score 


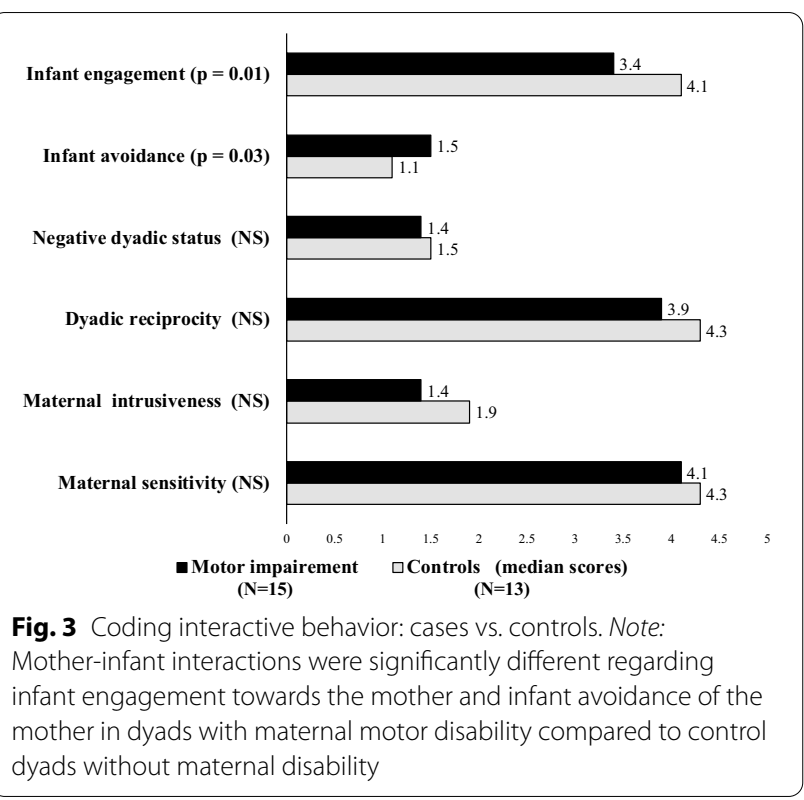

for infant engagement was significantly lower and the median score for infant avoidance was significantly greater in dyads with maternal motor impairment than in control ones.

\section{Discussion}

Our results suggest that in selected cases, with dedicated perinatal and parenting support, women with motor impairment resulting from a rare condition can achieve a successful pregnancy with a good short-term outcome in terms of infant development and health, and a reasonably good outcome in terms of mother-infant interactions. There was no correlation between the quality of motherinfant interactions and the degree of motor impairment. In addition, independence for activities of daily living did not predict independence for baby care. Half of the women who considered themselves as nearly or completely independent in daily activities declared that they were not when performing at least one parenting activity. All women with dependency in daily activity also felt dependent in parenting.

To the best of our knowledge, our exploratory study is the first to provide insight into child development and mother-infant interactions in women with motor disabilities due to a rare condition. Previous studies focused on fecundity $[2,31,32]$, health care consumption [1, 33], the risk of post-partum depression [34], somatic perinatal and maternal outcomes [35-38], women's expectations $[3,5,39]$, and the opinion of professional $[36,40,41]$ or lay people $[7,42]$.

Consequently, to date, recommendations have been issued mainly based on the opinions of experts [36, 41].
In an attempt to assess whether the environment provided by disabled mothers could lead to normal infant development, and safe mother- infant interactions, we focussed on infant development and mother-child interactions using a comprehensive clinical approach.

Our study is only exploratory given its numerous limitations. First, we failed to follow our initial plan, which was to use women with traumatic spine injury as a comparison group with women having a rare disease. We failed to recruit such pregnant women, because one of the obstetrical teams that was to be part of the project withdrew before we started inclusions. This made it impossible for us to determine the specific role of the etiology of the motor deficiency on parenthood. In our study, the conditions leading to motor disability were very heterogeneous and so were the degree and type of impairment. This is an obvious limitation in terms of generalization. The wide spectrum of disabilities represented, however, enabled us to show that the motherinfant interactions did not parallel the severity of motor dysfunctions. This is, in our view, a substantial result: one should not assume that interactions will go wrong on the basis that the mother has a severe motor impairment.

Second, our sample size is small, and self-selection of participants hampers generalization of our results. It is possible that mothers with severe social or parenting problems were not willing to participate. The professionals who offered women to participate also hypothesized that participants might have had a greater medical literacy than those who declined. This feeling, however, was not based on facts, since we did not ask potentially eligible persons why they choose to participate or not. Among participants, social support and social deprivation were similar to what is expected in the French population. The proportion of participants who had passed the final secondary education examination was slightly greater $(81.8 \%)$ than what was found in 2018 in France, i.e. 71.9 and $69.5 \%$, among women aged $25-34$ and 35-44 respectively. We reckon that the sample we analyzed is not representative of a hypothetical reference population of women with a motor disability. Indeed our goal was to provide an exploratory insight on the mechanism of parenting in young mothers with motor impairment, not to draw general conclusions on their parenting skills.

Evaluating obstetrical outcomes was not the main goal of our study. The numbers are too small and the conditions too heterogeneous to allow for a precise obstetrical interpretation. The main point however, is that there was no life-threatening maternal or neonatal complication, despite the fact that the rate of gestational diabetes $(18 \%)$, caesarean $(41 \%)$, prematurity (9\%) were greater than what is expected in the general population in France, i.e. respectively: $11 \%, 20 \%, 7 \%$. The rates of epidural 
analgesia and the rate of assisted vaginal delivery were unremarkable.

Generalization of our results should also take into account the fact that participants received intense preand post-natal parenting support from a dedicated institution, which is likely to have gradually optimized care since one of the authors (ET) founded it in the mid 1980 's.

Interpreting our results in terms of outcome is complex. The time span over which we assessed infant development and infant-mother interactions is not an issue, since each measurement took into account the baby's age. Short-term child development was unarguably standard. The rate of PIR-GAS scoring considered, perturbed or distressed was slightly above $50 \%$. This is more than expected in the general population; i.e. around $20-30 \%$ [43], but slightly less than what has been found in dyads following a premature delivery [44]. The fact that no PIR-GAS score was below 50 is reassuring, suggesting there was no case of child neglect. However, CIB assessment evidenced that infants are aware of their mothers' difficulties. Despite normal CIB maternal and dyadic scores, we found that the median infant avoidance score was greater and the infant engagement lower in dyads with maternal motor impairment than in controls. These differences are mild, yet statistically significant. Their magnitude is not greater than what we observed in women with no impairment who had a normal baby, but had been exposed to the prenatal finding of a minor variant at fetal screening ultrasound [30]. These findings support the idea that parenting support should be continued after the first year of the infant.

The very presence of the disability may have hampered the evaluation of interactions. For example, hyperkinetic movement disorders such as tremor or ataxia, present in 3 out of 22 participants, could possibly give a false impression of heightened intensity of emotion. The assessor was aware of such confounding effects, and was able to discern them with reasonable confidence.

Interestingly, low PIR-GAS scores were not correlated with the degree of motor impairment, the independence women perceived in their daily life, the age at which the disease started, the indices of social support or of social deprivation, or to the scores of anxiety and depression. This suggests that parenting is a complex process whose success cannot be anticipated by gross indicators such as motor impairment. It is also possible that we could not predict PIR-GAS based on maternal characteristics because factors we did not study played a key role, for example the situation of the co-parent and the family at large.
The fact that declared independence for baby care did not match with declared independence in activities of daily living assessed by the Barthel index was striking. This suggests that disability in parenting activity should be compensated for specifically, even in persons who otherwise declare they achieve independence in daily activities. What would be the key points to meet the needs of mothers with disabilities? Based on our clinical experience more so than on the results of this study, we believe the process could be as follows: (1) Explore what is needed to safely provide for the infant's basic needs, based on prenatal training, including simulation exercises. (2) For each specific activity e.g. handling, bathing, changing the baby, provide adaptations of the environment and human support needed for the baby and the parents to feel safe. In the most severe cases, such as tetraplegia, this may require to hire a person dedicated to helping the mother cope with her infant $24 \mathrm{~h}$ a day. We believe society should bear the costs related to parenting support in addition to those dedicated to activities of daily living.

In conclusion, our results support the hypothesis that at least in the short run and with extensive support, some women with motor deficiencies resulting from rare conditions may become successful parents. Parenting difficulties may occur, however, underlying the need for support based on what mothers express and on the clinical evaluation of the mother-infant interaction. In the future, larger surveys analyzing simpler outcome criteria are required to provide a wider picture of parenting skills and needs when parents have motor disabilities.

\section{Acknowledgements}

We thank the patients that enrolled in the study, the team of the "Service d'Aide à la Parentalité des Personnes en situation de Handicap", Paris, France, which made this study possible, the obstetrical, neonatal, and anesthetic teams of Pitié Salpêtrière Hospital, and specifically Dr Vauthier Brouzes, Prof Nizard, and Pr Foix L'Helias whose dedication to pregnant women with disabilities and their neonates was crucial to ensure a safe motherhood. We also thank the Institut Mutualiste Monsouris, Hôpital Louis Mourrier, Hôpital Bichat, Maternité des Bluets, Hopital Franco Britannique, Hopital Jean Verdier, Hôpital Mignot, Hôpital Robert Debré, and Clinique Sainte Félicité, who provided obstetrical care to some of the participants. We thank Mrs April Hail for kindly checking the syntax of our manuscript. We thank Mrs Karine Martin (Unité de Recherche Clinique, Pitié Salpêtrière Charles Foix) for project management.

\section{Authors' contributions}

Marc Dommergues contributed in designing the study, managed the data, did the analysis, contributed in writing the manuscript; Drina Candilis contributed in designing the study and writing the manuscript; Ludivine Becerra did the interviews, the videos, and contributed in writing the manuscript; Edith Thoueille was at the origin of the parenting support project, contributed in designing the research, and checked the manuscript; David Cohen contributed in writing the manuscript; Sylvie Viaux Savelon analyzed the videos, contributed in designing the study, and writing the manuscript. All authors read and approved the final manuscript. 


\section{Funding}

This research was made possible by a grant from the Fondation des Maladies Rares, Paris, France.

\section{Availability of data and materials}

The datasets generated during and/or analysed during the current study are available from the corresponding author on reasonable request.

\section{Declarations}

\section{Ethics approval and consent to participate}

The study was approved by the committee of protection of persons participating in clinical research (CPP Ile de France VI, 2016, April 25th decision) and declared as Clinical Trial (ID: NCT02727010).

\section{Consent for publication}

Mothers gave written informed consent to participate in the study. In the subgroup with a video of mother-infant interaction, both parents consented in written.

\section{Competing interests}

The authors have no competing interests.

\section{Author details}

${ }^{1}$ Department of Obstetrics and Gynecology, Hopital Pitié Salpêtrière APHP and Sorbonne Université, 83 Boulevard de l'Hopital, 75013 Paris, France. ${ }^{2}$ Université Paris Diderot, Paris, France. ${ }^{3}$ Service d'Aide à la Parentalité des Personnes en Situation de Handicap, Paris, France. ${ }^{4}$ Child Psychiatry, Hopital Pitié Salpêtrière APHP and Sorbonne Université, Paris, France.

Received: 7 December 2020 Accepted: 31 March 2021

Published online: 13 April 2021

\section{References}

1. Sumito D, Kurinczuk JK, Redshaw M, Gray R. Prevalence and impact of disability in women who had recently given birth in the UK. BMC Pregnancy Childbirth. 2012;12:31. https://doi.org/10.1186/1471-2393-12-31.

2. lezzoni LI, Yu J, Wint AJ, Smeltzer SC, Ecker JL. General health, health conditions and current pregnancy among US women with and without chronic physical disabilities. Disabil Health J. 2014;7(2):181-8.

3. Redshaw M, Malouf R, Gao H, Gray R. Women with disability: the experience of maternity care during pregnancy, labour and birth and the postnatal period. BMC Pregnancy Childbirth. 2013;13:174

4. Shpigelman CN. How to support the needs of mothers with physical disabilities. Disabil Rehabil. 2014;37:1-8.

5. Smeltzer SC, Mitra M, lezzoni LI, Long-Bellil L, Smith LD. Perinatal experiences of women with physical disabilities and their recommendations for clinicians. J Obstet Gynecol Neonatal Nurs. 2016;45(6):781-9.

6. Mitra M, Akobirshoev I, Sammet Moring N, Long-Bellil L, Smeltzer SC, Smith LD, lezzoni LI. Access to and satisfaction with prenatal care among pregnant women with physical disabilities: findings from a national survey. J Womens Health (Larchmt). 2017;26(12):1356-63. https://doi.org/ 10.1089/jwh.2016.6297.

7. Powell RM, Mitra M, Smeltzer SC, Long-Bellil LM, Smith LD, lezzoni LI. Family attitudes and reactions toward pregnancy among women with physical disabilities womens health issues. Maternal Health. 2017;27(3):345-50. https://doi.org/10.1016/j.whi.2017.01.003.

8. Walsh-Gallagher D, Sinclair M, Mc CR. The ambiguity of disabled women's experiences of pregnancy, childbirth and motherhood: a phenomenological understanding. Midwifery. 2012;28(2):156-62.

9. Mahoney Fl, Barthel DW. Functional evaluation : the Barthel Index. Md State Med J. 1965;14:61-5.

10. Labbe E, Blanquet M, Gerbaud L, Poirier G, Sass C, Vendittelli F, et al. A new reliable index to measure individual deprivation: the EPICES score. Eur J Public Health. 2015;25(4):604-9.

11. Sass C, Moulin J-J, Gueguen R, Abric L, Dauphinot V, Dupre C, Giordanella JP, Girard F, Guenot C, Labbe Emile, La Rosa E, Magnier P, Martin E, Royer B, Rubirola M, Gerbaud L. Le score EPICES : un score individuel de précarité.
Construction du score et mesure des relations avec des données de santé dans une population de 197389 personnes. Bull Epidémiologique Hebd. 2006(14):93-6.

12. Cutrona CE. Social support and stress in the transition to parenthood. J Abnorm Psychol. 1984;93(4):378-90.

13. Caron J. A validation of the Social Provisions Scale: the SPS-10 items Sante Ment Que. 2013;38(1):297-318.

14. Koelewijn JM, Sluijs AM, Vrijkotte TGM. Possible relationship between general and pregnancy related anxiety during the first half of pregnancy and the birth process: a prospective cohort study. BMJ Open. 2017;7:e013413.

15. Spielberger CD. State-Trait Anxiety Inventory for Adults (STAI-AD). APA PsycTests. 1983. https://doi.org/10.1037/t06496-000.

16. Gunning MD, Denison FC, Stockley CJ, Ho SP, Sandhu HK, Reynolds RM. Assessing maternal anxiety in pregnancy with the State-Trait Anxiety Inventory (STAI): issues of validity, location and participation. J Reprod Infant Psychol. 2010;28(3):266-73. https://doi.org/10.1080/0264683090 3487300.

17. Cox JL, Holden JM, Sagovsky R. Detection of postnatal depression. Development of the 10-item Edinburgh Postnatal Depression Scale. Br J Psychiatry. 1987;150:782-6.

18. Teissèdre $F, C$ Chabrol $H$. Detecting women at risk for postnatal depression using the Edinburgh Postnatal Depression Scale at 2 to 3 days postpartum. Can J Psychiatry. 2004;49(1):51-4.

19. Chabrol H, Teissedre F. Relation between Ediburgh Postnatal Depression Scale scores at 2-3 days and 4-6 weeks postpartum. J Reprod Infant Psychol. 2004:22(1):33-9.

20. Cardoso FGC, Formiga CKMR, Bizinotto T, Tessler RB, Rosa F. Concurrent validity of the Brunet-Lézine scale with the Bayley scale for Assessment of the development of preterm infants up to two years. Rev Paul Pediatr. 2017:35(2):144-50.

21. Treut LL, Poinso F, Grandgeorge P, Jouve E, Dugnat M, Sparrow J, et al. Infant psychomotor development in cases of maternal postpartum depression: observation of a mother and baby unit. Ment IIIn. 2018;10(1):7267.

22. Guedeney A, Fermanian J. A validity and reliability study of assessment and screening for sustained withdrawal reaction in infancy The Alarm Distress Baby Scale (ADBB). Infant Ment Health J. 2001;22(5):559-75.

23. Puura K, Mäntymaa M, Luoma I, Kaukonen P, Guedeney A, Salmelin $R$, et al. Infants' social withdrawal symptoms assessed with a direct infant observation method in primary health care. Infant Behav Dev. 2010;33(4):579-88.

24. Matthey S, Črnčec R, Hales A, Guedeney A. A description of the modified alarm distress baby scale (m-ADBB): an instrument to assess for infant social withdrawal. Infant Mental Health J. 2013;34:516-31.

25. Müller JM, Achtergarde S, Frantzmann H, Steinberg K, Skorozhenina O, Beyer $\mathrm{T}$, et al. Inter-rater reliability and aspects of validity of the parentinfant relationship global assessment scale (PIR-GAS). Child Adolesc Psychiatry Ment Health. 2013;7(1):17.

26. Fenichel E, Emde R, Egger H, Guedeney A, Wise B, Wright H. Présentation de la révision de la Classification Diagnostique $0-3$ ans (DC : 0-3R) Devenir. 2005; 17:347-60.

27. Keren M, Feldman R, Tyano S. Diagnoses and interactive patterns of infants referred to a community-based infant mental health clinic. J Am Acad Child Adolesc Psychiatry. 2001:40(1):27-35.

28. Silberstein D, Feldman R, Gardner J, Karmel B, Kuint J, Geva R. The mother-enfant feeding relationship across the first year and the development of feeding difficultiies in low-risk premature Infants. Infancy. 2009;14(5):501-25.

29. Viaux-Savelon S, Leclere C, Aidane E, Bodeau N, Camon-Senechal L, Vatageot S, et al. Validation de la version française du Coding Interactive Behavior sur une population d'enfants à la naissance et à 2 mois. Neuropsychiatrie de l'Enfance et de l'Adolescence. 2014;62(1):53-60.

30. Viaux-Savelon S, Dommergues M, Rosenblum O, Bodeau N, Aidane E Philippon $\mathrm{O}$, et al. Prenatal ultrasound screening: false positive soft markers may alter maternal representations and mother-infant interaction. PLOS ONE. 2012;7(1):e30935.

31. Horner-Johnson W, Darney BG, Kulkarni-Rajasekhara S, Quigley B, Caughey AB. Pregnancy among US women: differences by presence, type, and complexity of disability. Am J Obstet Gynecol. 2016; 214(4):529. e1-e9. 
32. Shandra CL, Hogan DP, Short SE. Planning for motherhood: fertility attitudes, desires and intentions among women with disabilities. Perspect Sex Reprod Health. 2014;46(4):203-10.

33. Gavin NI, Benedict MB, Adams EK. Health service use and outcomes among disabled Medicaid pregnant women. Womens Health Issues. 2006;16(6):313-22.

34. Mitra M, lezzoni LI, Zhang J, Long-Bellil LM, Smeltzer SC, Barton BA. Prevalence and risk factors for postpartum depression symptoms among women with disabilities. Matern Child Health J. 2015:19(2):362-72.

35. Le Liepvre H, Dinh A, Idiard-Chamois B, Chartier-Kastler E, Phé V, Even A, et al. Pregnancy in spinal cord-injured women, a cohort study of 37 pregnancies in 25 women. Spinal Cord. 2017;55(2):167-71.

36. Norwood F, Rudnik-Schöneborn S. Pregnancy in women with neuromuscular disorders: 5-7 November 2010, Naarden, The Netherlands. In: Disorders. N, editor. 179th ENMC international workshop; Naarden, The Netherlands 2012. p. 183-90.

37. Signore C, Spong CY, Krotoski D, Shinowara NL, Blackwell SC. Pregnancy in women with physical disabilities. Obstet Gynecol. 2011;117(4):935-47.

38. Guerby P, Vidal F, Bayoumeu F, Parant O. Paraplégie et grossesse : à propos d'une série rétrospective continue sur 11 années au CHU de Toulouse (Paraplegia and pregnancy). Journal de Gynécologie Obstétrique et Biologie de la Reproduction Journal de Gynecologie Obstetrique et Biologie de la reproduction. 2016;45:270-7.
39. Payne D, McPherson KM. Becoming mothers. Multiple sclerosis and motherhood: a qualitative study. Disabil Rehabil. 2010;32(8):629-38.

40. Bertschy S, Pannek J, Meyer T. Delivering care under uncertainty: Swiss providers' experiences in caring for women with spinal cord injury during pregnancy and childbirth - an expert interview study. BMC Pregnancy Childbirth. 2016;16(1):181

41. Argov Z, de Visser M. What we do not know about pregnancy in hereditary neuromuscular disorders. Neuromuscul Disord. 2009;19(10):675-9.

42. Parchomiuk M. Social context of disabled parenting. Sex Disabil. 2014;32:231-42.

43. Hatzinikolaou K, Karveli V, Skoubourdi A, Zarokosta F, Antonucci G, Visci G, et al. Using the Parent-Infant Relationship Global Assessment Scale to identify caregiver-infant/toddler dyads with abusive relationship patterns in six European countries. Infant Ment Health Journal. 2016;37(4):335-55.

44. Karabekiroğlu K, Akman I, Kuşçu Orhan \$̧, Kuşçu K, Altuncu E, Karabekiroğlu A, et al. Mother-child interactions of preterm toddlers. Noro Psikiyatr Ars. 2015;52(2):157-62.

\section{Publisher's Note}

Springer Nature remains neutral with regard to jurisdictional claims in published maps and institutional affiliations.
Ready to submit your research? Choose BMC and benefit from:

- fast, convenient online submission

- thorough peer review by experienced researchers in your field

- rapid publication on acceptance

- support for research data, including large and complex data types

- gold Open Access which fosters wider collaboration and increased citations

- maximum visibility for your research: over 100M website views per year

At BMC, research is always in progress.

Learn more biomedcentral.com/submissions 